\title{
A discussion on best proximity point and coupled best proximity point in partially ordered metric spaces
}

\author{
Binayak S Choudhury' , Nikhilesh Metiya², Mihai Postolache ${ }^{3 *}$ and Pulak Konar ${ }^{4}$
}

\section{"Correspondence:}

mihai@mathem.pub.ro

${ }^{3}$ Department of Mathematics and

Informatics, University Politehnica of

Bucharest, Bucharest, 060042,

Romania

Full list of author information is

available at the end of the article

\begin{abstract}
In this paper we establish some best proximity point results using generalized weak contractions with discontinuous control functions. The theorems are established in metric spaces with a partial order. We view the main problem in the paper as a problem of finding an optimal approximate solution of a fixed point equation. We also discuss several corollaries and give an illustrative example. We apply our result to obtain some coupled best proximity point results.
\end{abstract}

MSC: $47 \mathrm{H} 10 ; 54 \mathrm{H} 10 ; 54 \mathrm{H} 25$

Keywords: partially ordered set; control function; best proximity point; coupled best proximity point

\section{Introduction and mathematical preliminaries}

In this work we consider a problem of global optimization in the context of partially ordered metric spaces. Specifically it is a problem of finding the minimum distance between two subsets of a partially ordered metric space. We utilize a generalized weakly contractive non-self-map for this purpose. In fact non-self-maps have been utilized for the said purposes under a category of problems which has been termed the proximity point problems. This category of problems had its origin in the work of Eldred and Veeramani [1] in 2006 and has, in subsequent times, developed vastly through a large number of works. The following is the description of this problem. Let $(X, d)$ be a metric space. Let $A$ and $B$ be two subset of $X$. A pair $(a, b) \in A \times B$ is called a best proximity pair if $d(a, b)=d(A, B)=\inf \{d(x, y): x \in A$ and $y \in B\}$. If $A$ and $B$ are two non-empty subsets of a metric space $(X, d)$ and $T$ is a mapping from $A$ to $B$, then $d(x, T x) \geq d(A, B)$ for all $x \in A$. A point $z \in A$ is called a best proximity point (with respect to $T$ ) if at the point $z$ the function $d(x, T x)$ attains its global minimum with the value $d(A, B)$; that is, $d(z, T z)=d(A, B)$. Thus the problem is a problem of global minimization. In another approach to this problem, it can be viewed as an approximate fixed point problem [2]. We adopt this approach in this paper. The description of this viewpoint is in the following. For the mapping $T: A \rightarrow B$, the idea of a fixed point, that is, a point for which $x=T x$ is not pertinent when $A$ and $B$ are disjoint. Even in the cases where $A \cap B \neq \emptyset$, a fixed point of the function $T$ only exists under special conditions. But it may be possible to find some

(c) 2015 Choudhury et al. This article is distributed under the terms of the Creative Commons Attribution 4.0 International License (http://creativecommons.org/licenses/by/4.0/), which permits unrestricted use, distribution, and reproduction in any medium, provided you give appropriate credit to the original author(s) and the source, provide a link to the Creative Commons license, and indicate if changes were made. 
sort of approximate fixed point of $T$ by minimizing the function $d(x, T x)$. If the minimized value is $d(A, B)$, then we obtain a proximity point at which the proximity pair is realized. Thus the proximity point problem is to find an optimal approximate solution of the fixed point equation $T x=x$. Thus several methodologies available in the fixed point theory can be adapted to the situation. It is pertinent to point out that proximity point problems are different from best approximation problems which are not necessarily a global optimization problem. A best approximation theorem provides us with best approximate solutions which is not necessarily optimal. As an instance we consider the following Ky Fan best approximation theorem.

Theorem 1.1 ([3]) Let A be a non-empty compact convex subset of a normed linear space $X$ and $T: A \rightarrow X$ be a continuous function. Then there exists $x \in A$ such that

$$
\|x-T x\|=d(T x, A)=\inf \{\|T x-a\|: a \in A\} .
$$

The point $x$ in the above theorem need not provide with the optimum value of $\|x-T x\|$. On the contrary the best proximity point theorems assert that the approximate solution of the fixed point equation is also globally optimal. Technically, through a best proximity point result we obtain the global minima of the real valued function $x \mapsto d(x, T x)$ by constraining an approximate solution of $x=T x$ to satisfy $d(x, T x)=\operatorname{dist}(A, B)$.

In the proximity point problems, there are several uses of functions satisfying contraction conditions as, for instances, in [4-16]. The contraction condition in the context for fixed point theory first appeared in the celebrated work of Banach [17], which, incidentally, is also recognized as the source of fixed point theory. Afterwards, contractive conditions have taken a large place in metric fixed point theory. For a survey of this development we refer to [18]. Weak contractions were introduced in Hilbert spaces by Alber and GuerreDelabriere [19] and subsequently extended to metric spaces by Rhoades [20]. This is a condition which is intermediate to contraction and nonexpansion. Weak contractions were studied in metric spaces and in partially ordered metric spaces through the works [21-30]. Particularly in 2013, a generalized weak contraction inequality was given by Choudhury et $a l$. [24] which was utilized to obtain coincidence and coupled coincidence point theorems in partially ordered metric spaces.

It may be mentioned that coupled fixed point problems, and their allied problems, have attracted a large general interest amongst mathematician after the appearance of the work of Gnana Bhaskar and Lakshmikantham [31] in 2006 in which a coupled contraction mapping theorem was established although the concept of coupled fixed point was introduced in 1987 in the work of Guo and Lakshmikantham [32]. Amongst several works in the above mentioned area there are also coupled weak contraction results as, for instance, in [33] and [24]. Coupled contractions have also been utilized in best proximity problems in works like [34-37].

The purpose of the paper is to obtain proximity point results in partially ordered metric spaces by utilizing the weak contractive inequality obtained in [24]. In this context it is to be mentioned that the weak contraction has already been used to obtain proximity point theorem by Sankar Raj [16]. We have an application of our main result to a product space through which we obtain a coupled proximity point result. An illustrative example is also discussed. 
The following are the requisite mathematical concepts for the discussions in this paper. Let $(X, \preceq)$ be a partially ordered set and suppose that $d$ is a metric on $X$. Unless otherwise specified, it is assumed throughout this section that $A$ and $B$ are two non-empty subsets of the metric space $(X, d)$. In the following we give some notation and notions:

$$
\begin{aligned}
& d(A, B)=\inf \{d(x, y): x \in A \text { and } y \in B\}, \\
& A_{0}=\{x \in A: d(x, y)=d(A, B) \text { for some } y \in B\}
\end{aligned}
$$

and

$$
B_{0}=\{y \in B: d(x, y)=d(A, B) \text { for some } x \in A\} .
$$

It is to be noted that for every $x \in A_{0}$ there exists $y \in B_{0}$ such that $d(x, y)=d(A, B)$ and conversely, for every $y \in B_{0}$ there exists $x \in A_{0}$ such that $d(x, y)=d(A, B)$.

Definition 1.1 ( $P$-property [16]) Let $A$ and $B$ be two non-empty subsets of a metric space $(X, d)$ with $A_{0} \neq \emptyset$. Then the pair $(A, B)$ is said to have the $P$-property if, for any $x_{1}, x_{2} \in A_{0}$ and $y_{1}, y_{2} \in B_{0}$,

$$
\left.\begin{array}{l}
d\left(x_{1}, y_{1}\right)=\operatorname{dist}(A, B), \\
d\left(x_{2}, y_{2}\right)=\operatorname{dist}(A, B)
\end{array}\right\} \Rightarrow d\left(x_{1}, x_{2}\right)=d\left(y_{1}, y_{2}\right)
$$

In [4], Abkar and Gabeleh show that every non-empty, bounded, closed, and convex pair of subsets of a uniformly convex Banach space has the $P$-property. Some non-trivial examples of a non-empty pair of subsets which satisfies the $P$-property are given in [4].

Definition 1.2 A mapping $T: A \rightarrow A$ is said to be increasing if for all $x_{1}, x_{2} \in A$,

$$
x_{1} \preceq x_{2} \quad \Rightarrow \quad T x_{1} \preceq T x_{2} .
$$

Definition 1.3 ([7]) A mapping $T: A \rightarrow B$ is said to be proximally increasing if for all $u_{1}, u_{2}, x_{1}, x_{2} \in A$,

$$
\left.\begin{array}{l}
x_{1} \preceq x_{2}, \\
d\left(u_{1}, T x_{1}\right)=d(A, B), \\
d\left(u_{2}, T x_{2}\right)=d(A, B)
\end{array}\right\} \Rightarrow u_{1} \preceq u_{2} .
$$

One can see that, for a self-mapping, the notion of proximally increasing reduces to that of an increasing mapping.

Definition 1.4 A mapping $T: A \rightarrow B$ is said to be proximally increasing on $A_{0}$ if for all $u_{1}, u_{2}, x_{1}, x_{2} \in A_{0}$,

$$
\left.\begin{array}{l}
x_{1} \preceq x_{2}, \\
d\left(u_{1}, T x_{1}\right)=d(A, B), \\
d\left(u_{2}, T x_{2}\right)=d(A, B)
\end{array}\right\} \Rightarrow u_{1} \preceq u_{2} .
$$


Definition 1.5 An element $x^{*} \in A$ is said to be best proximity point of the mapping $T: A \rightarrow B$ if $d\left(x^{*}, T x^{*}\right)=d(A, B)$.

Definition 1.6 ([31]) A mapping $F: A \times A \rightarrow A$ is said to have the mixed monotone property if $F$ is monotone nondecreasing in its first argument and is monotone nonincreasing in its second argument; that is, if

$$
x_{1}, x_{2} \in A, \quad x_{1} \preceq x_{2} \quad \Rightarrow \quad F\left(x_{1}, y\right) \preceq F\left(x_{2}, y\right) \quad \text { for all } y \in A
$$

and

$$
y_{1}, y_{2} \in A, \quad y_{1} \preceq y_{2} \quad \Rightarrow \quad F\left(x, y_{1}\right) \succeq F\left(x, y_{2}\right) \quad \text { for all } x \in A \text {. }
$$

Definition 1.7 ([35]) A mapping $F: A \times A \rightarrow B$ is said to have the proximal mixed monotone property if $F(x, y)$ is proximally nondecreasing in $x$ and is proximally nonincreasing in $y$; that is, for all $x, y \in A$,

$$
\left.\begin{array}{l}
x_{1} \preceq x_{2}, \\
d\left(u_{1}, F\left(x_{1}, y\right)\right)=d(A, B), \\
d\left(u_{2}, F\left(x_{2}, y\right)\right)=d(A, B)
\end{array}\right\} \Rightarrow u_{1} \preceq u_{2}
$$

and

$$
\left.\begin{array}{l}
y_{1} \preceq y_{2}, \\
d\left(v_{1}, F\left(x, y_{1}\right)\right)=d(A, B), \\
d\left(v_{2}, F\left(x, y_{2}\right)\right)=d(A, B)
\end{array}\right\} \Rightarrow v_{2} \preceq v_{1},
$$

where $x_{1}, x_{2}, y_{1}, y_{2}, u_{1}, u_{2}, v_{1}, v_{2} \in A$.

One can see that, if $A=B$ in the above definition, the notion of the proximal mixed monotone property reduces to that of the mixed monotone property.

In Section 3, while applying the results of Section 2 to obtain coupled best proximity point results, we will require the property in Definition 1.7 to be satisfied only on an appropriate subset of $A \times A$. For that purpose we introduce the following definition.

Definition 1.8 A mapping $F: A \times A \rightarrow B$ is said to have the proximal mixed monotone property on $A_{0} \times A_{0}$ if for all $x, y \in A_{0}$,

$$
\left.\begin{array}{l}
x_{1} \preceq x_{2}, \\
d\left(u_{1}, F\left(x_{1}, y\right)\right)=d(A, B), \\
d\left(u_{2}, F\left(x_{2}, y\right)\right)=d(A, B)
\end{array}\right\} \Rightarrow u_{1} \preceq u_{2}
$$

and

$$
\left.\begin{array}{l}
y_{1} \preceq y_{2}, \\
d\left(v_{1}, F\left(x, y_{1}\right)\right)=d(A, B), \\
d\left(v_{2}, F\left(x, y_{2}\right)\right)=d(A, B)
\end{array}\right\} \Rightarrow v_{2} \preceq v_{1},
$$

where $x_{1}, x_{2}, y_{1}, y_{2}, u_{1}, u_{2}, v_{1}, v_{2} \in A_{0}$. 
Definition 1.9 ([36]) An element $\left(x^{*}, y^{*}\right) \in A \times A$, is called a coupled best proximity point of the mapping $F: A \times A \rightarrow B$ if $d\left(x^{*}, F\left(x^{*}, y^{*}\right)\right)=d(A, B)$ and $d\left(y^{*}, F\left(y^{*}, x^{*}\right)\right)=d(A, B)$.

The speciality of coupled proximity points is that they provide for the realization of the minimum distance in two ways simultaneously.

In our results in the following sections we will use two classes of functions. We denote by $\Psi$ the set of all functions $\psi:[0, \infty) \rightarrow[0, \infty)$ satisfying

$\left(\mathrm{i}_{\psi}\right) \quad \psi$ is continuous and $\psi(t)=0$ if and only if $t=0$;

and by $\Theta$ we denote the set of all functions $\alpha:[0, \infty) \rightarrow[0, \infty)$ such that

$\left(\mathrm{i}_{\alpha}\right) \quad \alpha$ is bounded on any bounded interval in $[0, \infty)$,

(ii $\alpha) \alpha$ is continuous at 0 and $\alpha(0)=0$.

\section{Main results}

Theorem 2.1 Let $(X, \preceq)$ be a partially ordered set and suppose that there is a metric d on $X$ such that $(X, d)$ is a complete metric space. Let $(A, B)$ be a pair of non-empty closed subsets of $X$ such that $A_{0}$ is non-empty closed and $(A, B)$ satisfies the P-property. Let $T: A \rightarrow B$ be a mapping such that $T\left(A_{0}\right) \subseteq B_{0}$ and $T$ is proximally increasing on $A_{0}$. Suppose that there exist $\psi \in \Psi$ and $\varphi, \theta \in \Theta$ such that

$$
\psi(x) \leq \varphi(y) \quad \Rightarrow \quad x \leq y
$$

for any sequence $\left\{x_{n}\right\}$ in $[0, \infty)$ with $x_{n} \rightarrow t>0$,

$$
\psi(t)-\varlimsup \varphi\left(x_{n}\right)+\underline{\lim } \theta\left(x_{n}\right)>0,
$$

and for all $x, y \in A_{0}$ with $x \succeq y$,

$$
\psi(d(T x, T y)) \leq \varphi(d(x, y))-\theta(d(x, y)) .
$$

\section{Suppose either}

(a) $T$ is continuous or

(b) if $\left\{x_{n}\right\}$ is a nondecreasing sequence in $X$ such that $x_{n} \rightarrow x$, then $x_{n} \preceq x$ for all $n \geq 0$.

Also, suppose that there exist elements $x_{0}, x_{1} \in A_{0}$ such that $d\left(x_{1}, T x_{0}\right)=d(A, B)$ and $x_{0} \preceq x_{1}$. Then $T$ has a best proximity point in $A_{0}$; that is, there exists an element $x^{*} \in A_{0}$ such that $d\left(x^{*}, T x^{*}\right)=d(A, B)$.

Proof By the conditions of Theorem 2.1 there exist elements $x_{0}, x_{1} \in A_{0}$ such that

$$
d\left(x_{1}, T x_{0}\right)=d(A, B) \text { and } \quad x_{0} \preceq x_{1} .
$$

Because of the fact that $T\left(A_{0}\right) \subseteq B_{0}$, there exists an element $x_{2} \in A_{0}$ such that

$$
d\left(x_{2}, T x_{1}\right)=d(A, B) .
$$

Since $T$ is proximally increasing on $A_{0}$, we get $x_{1} \preceq x_{2}$. Continuing this process, we construct a sequence $\left\{x_{n}\right\}$ in $A_{0}$ such that

$$
d\left(x_{n+1}, T x_{n}\right)=d(A, B) \quad \text { for all } n \geq 0
$$


with

$$
x_{0} \preceq x_{1} \preceq x_{2} \preceq \cdots \preceq x_{n} \preceq x_{n+1} \cdots
$$

Since $(A, B)$ satisfies the $P$-property, we conclude that

$$
d\left(x_{n}, x_{n+1}\right)=d\left(T x_{n-1}, T x_{n}\right) \quad \text { for all } n \geq 1 \text {. }
$$

Let $R_{n}=d\left(x_{n+1}, x_{n}\right)$, for all $n \geq 0$. Using (2.3), (2.5), and (2.6), we have

$$
\psi\left(d\left(x_{n+2}, x_{n+1}\right)\right)=\psi\left(d\left(T x_{n+1}, T x_{n}\right)\right) \leq \varphi\left(d\left(x_{n+1}, x_{n}\right)\right)-\theta\left(d\left(x_{n+1}, x_{n}\right)\right)
$$

that is,

$$
\psi\left(R_{n+1}\right) \leq \varphi\left(R_{n}\right)-\theta\left(R_{n}\right),
$$

which, in view of the fact that $\theta \geq 0$, yields $\psi\left(R_{n+1}\right) \leq \varphi\left(R_{n}\right)$, which by (2.1) implies that $R_{n+1} \leq R_{n}$, for all positive integer $n$; that is, $\left\{R_{n}\right\}$ is a monotone decreasing sequence. Hence there exists an $r \geq 0$ such that

$$
R_{n}=d\left(x_{n+1}, x_{n}\right) \rightarrow r \quad \text { as } n \rightarrow \infty .
$$

Taking the limit supremum in both sides of (2.7), using (2.8), the property of $\varphi$ and $\theta$, and the continuity of $\psi$, we obtain

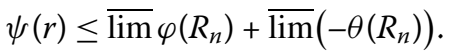

Since $\varlimsup\left(-\theta\left(R_{n}\right)\right)=-\underline{\lim } \theta\left(R_{n}\right)$, it follows that

$$
\psi(r) \leq \varlimsup i m \varphi\left(R_{n}\right)-\underline{\lim } \theta\left(R_{n}\right)
$$

that is,

$$
\psi(r)-\varlimsup \overline{\lim } \varphi\left(R_{n}\right)+\underline{\lim } \theta\left(R_{n}\right) \leq 0,
$$

which by (2.2) is a contradiction unless $r=0$. Therefore,

$$
R_{n}=d\left(x_{n+1}, x_{n}\right) \rightarrow 0 \quad \text { as } n \rightarrow \infty .
$$

Next we show that $\left\{x_{n}\right\}$ is a Cauchy sequence.

Suppose that $\left\{x_{n}\right\}$ is not a Cauchy sequence. Then there exists an $\epsilon>0$ for which we can find two sequences of positive integers $\{m(k)\}$ and $\{n(k)\}$ such that for all positive integers $k, n(k)>m(k)>k$, and $d\left(x_{m(k)}, x_{n(k)}\right) \geq \epsilon$. Assuming that $n(k)$ is the smallest such positive integer, we get

$$
n(k)>m(k)>k, \quad d\left(x_{m(k)}, x_{n(k)}\right) \geq \epsilon \quad \text { and } \quad d\left(x_{m(k)}, x_{n(k)-1}\right)<\epsilon .
$$


Now,

$$
\epsilon \leq d\left(x_{m(k)}, x_{n(k)}\right) \leq d\left(x_{m(k)}, x_{n(k)-1}\right)+d\left(x_{n(k)-1}, x_{n(k)}\right)
$$

that is,

$$
\epsilon \leq d\left(x_{m(k)}, x_{n(k)}\right) \leq \epsilon+d\left(x_{n(k)-1}, x_{n(k)}\right) .
$$

Letting $k \rightarrow \infty$ in the above inequality and using (2.9), we have

$$
\lim _{k \rightarrow \infty} d\left(x_{m(k)}, x_{n(k)}\right)=\epsilon
$$

Again,

$$
d\left(x_{m(k)+1}, x_{n(k)+1}\right) \leq d\left(x_{m(k)+1}, x_{m(k)}\right)+d\left(x_{m(k)}, x_{n(k)}\right)+d\left(x_{n(k)+1}, x_{n(k)}\right)
$$

and

$$
d\left(x_{m(k)}, x_{n(k)}\right) \leq d\left(x_{m(k)+1}, x_{m(k)}\right)+d\left(x_{m(k)+1}, x_{n(k)+1}\right)+d\left(x_{n(k)+1}, x_{n(k)}\right) .
$$

Letting $k \rightarrow \infty$ in the above inequalities, using (2.9) and (2.10), we have

$$
\lim _{k \rightarrow \infty} d\left(x_{m(k)+1}, x_{n(k)+1}\right)=\epsilon
$$

From (2.4), we have

$$
d\left(x_{m(k)+1}, T x_{m(k)}\right)=d\left(x_{n(k)+1}, T x_{n(k)}\right)=d(A, B) .
$$

By the $P$-property, it follows that

$$
d\left(x_{n(k)+1}, x_{m(k)+1}\right)=d\left(T x_{n(k)}, T x_{m(k)}\right) .
$$

As $n(k)>m(k), x_{n(k)} \succeq x_{m(k)}$, applying (2.3), we have

$$
\psi\left(d\left(x_{n(k)+1}, x_{m(k)+1}\right)\right)=\psi\left(d\left(T x_{n(k)}, T x_{m(k)}\right)\right) \leq \varphi\left(d\left(x_{n(k)}, x_{m(k)}\right)\right)-\theta\left(d\left(x_{n(k)}, x_{m(k)}\right)\right) .
$$

Taking the limit supremum in both sides of the above inequality, using (2.10), (2.11), the property of $\varphi$ and $\theta$, and the continuity of $\psi$, we obtain

$$
\psi(\epsilon) \leq \varlimsup \lim \varphi\left(d\left(x_{n(k)}, x_{m(k)}\right)\right)+\varlimsup \lim \left(-\theta\left(d\left(x_{n(k)}, x_{m(k)}\right)\right)\right) .
$$

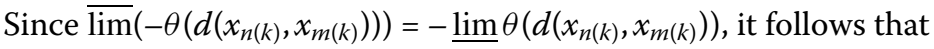

$$
\psi(\epsilon) \leq \varlimsup \lim \varphi\left(d\left(x_{n(k)}, x_{m(k)}\right)\right)-\underline{\lim } \theta\left(d\left(x_{n(k)}, x_{m(k)}\right)\right) ;
$$

that is,

$$
\psi(\epsilon)-\varlimsup \varphi\left(d\left(x_{n(k)}, x_{m(k)}\right)\right)+\underline{\lim } \theta\left(d\left(x_{n(k)}, x_{m(k)}\right)\right) \leq 0,
$$


which is a contradiction by (2.10) and (2.2). Therefore, $\left\{x_{n}\right\}$ is a Cauchy sequence in $A_{0}$. Since $(X, d)$ is complete and $A_{0} \subseteq X$ is closed, $A_{0}$ is also complete. From the completeness of $A_{0}$, there exists $x^{*} \in A_{0}$ such that

$$
\lim _{n \rightarrow \infty} x_{n}=x^{*} ; \text { that is, } \quad \lim _{n \rightarrow \infty} d\left(x_{n}, x^{*}\right)=0 .
$$

Let the condition (a) hold.

Taking $n \rightarrow \infty$ in (2.4) and using the continuity of $T$, we have $d\left(x^{*}, T x^{*}\right)=d(A, B)$; that is, $x^{*}$ is best proximity point of $T$.

Let the condition (b) hold.

By the condition (b) of the theorem, (2.5), and (2.12), we have $x_{n} \preceq x^{*}$ for all $n \geq N$.

Since $x^{*} \in A_{0}$, we have $T x^{*} \in T\left(A_{0}\right) \subseteq B_{0}$ and therefore there exists a point $z \in A_{0}$ such that

$$
d\left(z, T x^{*}\right)=d(A, B)
$$

Since $d\left(x_{n+1}, T x_{n}\right)=d(A, B)$ (by (2.4)), applying the $P$-property of $(A, B)$, we get

$$
d\left(z, x_{n+1}\right)=d\left(T x^{*}, T x_{n}\right) .
$$

Applying (2.3), we have

$$
\psi\left(d\left(z, x_{n+1}\right)\right)=\psi\left(d\left(T x^{*}, T x_{n}\right)\right) \leq \varphi\left(d\left(x^{*}, x_{n}\right)\right)-\theta\left(d\left(x^{*}, x_{n}\right)\right) .
$$

Taking the limit as $n \rightarrow \infty$ in the above inequality, using (2.12) and the property $\left(\mathrm{ii}_{\alpha}\right)$ of $\varphi$ and $\theta$, and the properties of $\psi$, we obtain

$$
\lim _{n \rightarrow \infty} \psi\left(d\left(z, x_{n+1}\right)\right) \leq \lim _{n \rightarrow \infty} \varphi\left(d\left(x^{*}, x_{n}\right)\right)-\lim _{n \rightarrow \infty} \theta\left(d\left(x^{*}, x_{n}\right)\right) ;
$$

that is, $\psi\left(d\left(z, x^{*}\right)\right) \leq 0$, which implies that $d\left(x^{*}, z\right)=0$; that is, $z=x^{*}$. Thus, we have $d\left(x^{*}, T x^{*}\right)=d(A, B)$; that is, $x^{*}$ is best proximity point of $T$.

Considering $\psi$ to be the identity mapping and $\theta(t)=0$ for all $t \in[0, \infty)$ in Theorem 2.1 we have the following corollary.

Corollary 2.1 Let $(X, \preceq)$ be a partially ordered set and suppose that there is a metric d on $X$ such that $(X, d)$ is a complete metric space. Let $(A, B)$ be a pair of non-empty closed subsets of $X$ such that $A_{0}$ is non-empty closed and $(A, B)$ satisfies the P-property. Let $T: A \rightarrow B$ be a mapping such that $T\left(A_{0}\right) \subseteq B_{0}$ and $T$ is proximally increasing on $A_{0}$. Suppose that there exists $\varphi \in \Theta$ such that for any sequence $\left\{x_{n}\right\}$ in $[0, \infty)$ with $x_{n} \rightarrow t>0, \varlimsup \varphi\left(x_{n}\right)<t$, and for all $x, y \in A_{0}$ with $x \geq y$,

$$
d(T x, T y) \leq \varphi(d(x, y)) .
$$

\section{Suppose either}

(a) $T$ is continuous or

(b) if $\left\{x_{n}\right\}$ is a nondecreasing sequence in $A_{0}$ such that $x_{n} \rightarrow x$, then $x_{n} \preceq x$ for all $n \geq 0$. 
Also, suppose that there exist elements $x_{0}, x_{1} \in A_{0}$ such that $d\left(x_{1}, T x_{0}\right)=d(A, B)$ and $x_{0} \preceq x_{1}$. Then $T$ has a best proximity point in $A_{0}$.

Considering $\varphi$ to be the function $\psi$ in Theorem 2.1 we have the following corollary.

Corollary 2.2 Let $(X, \preceq)$ be a partially ordered set and suppose that there is a metric d on $X$ such that $(X, d)$ is a complete metric space. Let $(A, B)$ be a pair of non-empty closed subsets of $X$ such that $A_{0}$ is non-empty closed and $(A, B)$ satisfies the P-property. Let $T: A \rightarrow B$ be a mapping such that $T\left(A_{0}\right) \subseteq B_{0}$ and $T$ is proximally increasing on $A_{0}$. Suppose that there exist $\psi \in \Psi$ and $\theta \in \Theta$ such that for any sequence $\left\{x_{n}\right\}$ in $[0, \infty)$ with $x_{n} \rightarrow t>0$, $\underline{\lim } \theta\left(x_{n}\right)>0$, and for all $x, y \in A_{0}$ with $x \succeq y$,

$$
\psi(d(T x, T y)) \leq \psi(d(x, y))-\theta(d(x, y)) .
$$

\section{Suppose either}

(a) $T$ is continuous or

(b) if $\left\{x_{n}\right\}$ is a nondecreasing sequence in $A_{0}$ such that $x_{n} \rightarrow x$, then $x_{n} \preceq x$ for all $n \geq 0$.

Also, suppose that there exist elements $x_{0}, x_{1} \in A_{0}$ such that $d\left(x_{1}, T x_{0}\right)=d(A, B)$ and $x_{0} \preceq x_{1}$. Then $T$ has a best proximity point in $A_{0}$.

Considering $\psi$ and $\varphi$ to be the identity mappings and $\theta(t)=(1-k) t$, where $0 \leq k<1$ in Theorem 2.1, we have the following corollary.

Corollary 2.3 Let $(X, \preceq)$ be a partially ordered set and suppose that there is a metric $d$ on $X$ such that $(X, d)$ is a complete metric space. Let $(A, B)$ be a pair of non-empty closed subsets of $X$ such that $A_{0}$ is non-empty closed and $(A, B)$ satisfies the P-property. Let $T: A \rightarrow B$ be a mapping such that $T\left(A_{0}\right) \subseteq B_{0}$ and $T$ is proximally increasing on $A_{0}$. Assume that there exists $k \in[0,1)$ such that, for all $x, y \in A_{0}$ with $x \succeq y$,

$$
d(T x, T y) \leq k d(x, y) .
$$

Suppose either

(a) $T$ is continuous or

(b) if $\left\{x_{n}\right\}$ is a nondecreasing sequence in $A_{0}$ such that $x_{n} \rightarrow x$, then $x_{n} \preceq x$ for all $n \geq 0$.

Also, suppose that there exist elements $x_{0}, x_{1} \in A_{0}$ such that $d\left(x_{1}, T x_{0}\right)=d(A, B)$ and $x_{0} \preceq x_{1}$. Then $T$ has a best proximity point in $A_{0}$.

In the following, our aim is to prove the existence and uniqueness of the best proximity point in Theorem 2.1.

Theorem 2.2 In addition to the hypotheses of Theorem 2.1, suppose that for every $x, y \in A_{0}$ there exists $u \in A_{0}$ such that $u$ is comparable to $x$ and $y$. Then $T$ has a unique best proximity point.

Proof From Theorem 2.1, the set of best proximity point $T$ is non-empty. Suppose $x, y \in A_{0}$ are two best proximity points of $T$; that is,

$$
d(x, T x)=d(A, B) \quad \text { and } \quad d(y, T y)=d(A, B) .
$$

Now, we show that $x=y$. 
By the assumption, there exists $u \in A_{0}$ such that $u$ is comparable with $x$ and $y$.

Put $u_{0}=u$. Suppose that

$$
u_{0} \preceq x \quad \text { (the proof is similar in the other case). }
$$

Since $T\left(A_{0}\right) \subseteq B_{0}$ and $u_{0}=u \in A_{0}$, there exists $u_{1} \in A_{0}$ such that

$$
d\left(u_{1}, T u_{0}\right)=d(A, B)
$$

Since $T$ is proximally increasing on $A_{0}$, from (2.16), (2.17), and (2.18) we have

$$
u_{1} \preceq x .
$$

Continuing this process, we construct a sequence $\left\{u_{n}\right\}$ in $A_{0}$ such that

$$
d\left(u_{n+1}, T u_{n}\right)=d(A, B) \quad \text { for all } n \geq 0 \text { and } u_{n} \preceq x .
$$

Since $(A, B)$ satisfies the $P$-property, we conclude from (2.16) and (2.20) that

$$
d\left(x, u_{n+1}\right)=d\left(T x, T u_{n}\right) \quad \text { for all } n \geq 0 \text { and } u_{n} \preceq x .
$$

Let $R_{n}=d\left(x, u_{n}\right)$. Since $x \succeq u_{n}$ using the contractive condition (2.3), for all $n \geq 1$, we have

$$
\psi\left(d\left(x, u_{n+1}\right)\right)=\psi\left(d\left(T x, T u_{n}\right)\right) \leq \varphi\left(d\left(x, u_{n}\right)\right)-\theta\left(d\left(x, u_{n}\right)\right)
$$

that is, $\psi\left(R_{n+1}\right) \leq \varphi\left(R_{n}\right)-\theta\left(R_{n}\right)$, which, in view of the fact that $\theta \geq 0$, yields $\psi\left(R_{n+1}\right) \leq$ $\varphi\left(R_{n}\right)$, which by (2.1) implies that $R_{n+1} \leq R_{n}$, for all positive integer $n$, that is, $\left\{R_{n}\right\}$ is a monotone decreasing sequence.

Then as in the proof of Theorem 2.1, we have

$$
\lim _{n \rightarrow \infty} R_{n}=\lim _{n \rightarrow \infty} d\left(x, u_{n}\right)=0 .
$$

Similarly, we show that

$$
\lim _{n \rightarrow \infty} d\left(y, u_{n}\right)=0
$$

By the triangle inequality, and using (2.22) and (2.23), we have

$$
d(x, y) \leq\left[d\left(x, u_{n}\right)+d\left(u_{n}, y\right)\right] \rightarrow 0 \quad \text { as } n \rightarrow \infty .
$$

Hence $x=y$; that is, the best proximity point of $T$ is unique.

Example 2.1 Assume the complete metric space $\left(X=\mathbb{R}^{2}, d\right)$, where the metric $d$ is defined as $d(x, y)=\left|x_{1}-x_{2}\right|+\left|y_{1}-y_{2}\right|$, for $x=\left(x_{1}, y_{1}\right), y=\left(y_{1}, y_{2}\right) \in X$. We define a partial order $\preceq$ on $X$ such that $(x, y) \leq(u, v)$ if and only if $x \leq u$ and $y \leq v$, for all $(x, y),(u, v) \in X$. 
Let $A=\{(x, 1): 0 \leq x \leq 1\}, B=\{(x,-1): 0 \leq x \leq 1\}, A_{0}=\left\{\left(\frac{x}{2}, 1\right): 0 \leq x \leq 1\right\}$, and $B_{0}=B$. Consider $T: A \rightarrow B, T(x, 1)=\left(\frac{x}{2},-1\right)$. It is clear that $d(A, B)=2, A_{0} \subseteq A$, and $T\left(A_{0}\right) \subseteq B_{0}$. Also $(A, B)$ satisfies $P$-property.

Now we show that $T$ is proximally increasing on $A_{0}$. In this respect, let $\left(\frac{x}{2}, 1\right),\left(\frac{u}{2}, 1\right)$, $\left(\frac{y}{2}, 1\right),\left(\frac{v}{2}, 1\right) \in A_{0}$ with $\left(\frac{y}{2}, 1\right) \preceq\left(\frac{v}{2}, 1\right)$.

We have

$$
2=d\left(\left(\frac{x}{2}, 1\right), T\left(\frac{y}{2}, 1\right)\right)=d\left(\left(\frac{x}{2}, 1\right),\left(\frac{y}{4},-1\right)\right)=\left|x-\frac{y}{4}\right|+2
$$

and

$$
2=d\left(\left(\frac{u}{2}, 1\right), T\left(\frac{v}{2}, 1\right)\right)=d\left(\left(\frac{u}{2}, 1\right),\left(\frac{v}{4},-1\right)\right)=\left|u-\frac{v}{4}\right|+2,
$$

which implies that $x=\frac{y}{4}$ and $u=\frac{v}{4}$.

We see that $\left(\frac{y}{2}, 1\right) \preceq\left(\frac{v}{2}, 1\right)$ implies $\frac{y}{2} \leq \frac{v}{2}$; that is, $\frac{y}{4} \leq \frac{v}{4}$; that is, $x \leq u$. Now $x \leq u$ implies $\left(\frac{x}{2}, 1\right) \preceq\left(\frac{u}{2}, 1\right)$. Hence $T$ is proximally increasing on $A_{0}$.

Let $\psi, \varphi, \theta:[0, \infty) \rightarrow[0, \infty)$ be given, respectively, by the formulas

$$
\psi(t)=t^{2}, \quad \varphi(t)=\left\{\begin{array}{ll}
\frac{1}{2}[t]^{2}, & \text { if } t \in[3,4], \\
t, & \text { otherwise, }
\end{array} \quad \theta(t)= \begin{cases}\frac{1}{4}[t]^{2}, & \text { if } t \in[3,4] \\
0, & \text { otherwise }\end{cases}\right.
$$

Then $\psi, \varphi$, and $\theta$ have the properties mentioned in Theorem 2.1.

Here all of the conditions of Theorems 2.1 and 2.2 are satisfied and it is seen that $x^{*}=$ $(0,1)$ in $A$ is the unique best proximity point of $T$ in $A_{0}$.

Remark 2.1 In the above example, $\psi$ is not the identity mapping and not identical with $\varphi$, and $\theta(t) \neq 0$, for all $t \in[0, \infty)$. Therefore, Corollaries 2.1, 2.2, and 2.3 are not applicable to this example and hence Theorem 2.1 properly contains its Corollaries 2.1, 2.2, and 2.3.

Remark 2.2 Theorem 2.1 generalizes the main result in [16]. The main result in [16] is not applicable to this example and hence the generalization is proper.

\section{Applications to coupled best proximity point results}

In this section we make an application of the results of Section 2 to obtain new coupled proximity point results. The results are obtained through the construction of a product space to which we apply our theorem.

With the help of partially ordered set $(X, \preceq)$ we endow the product space $X \times X$ with the following partial order:

$$
\text { for }(x, y),(u, v) \in X \times X, \quad(u, v) \preceq(x, y) \quad \Leftrightarrow \quad x \succeq u, \quad y \preceq v .
$$

With the help of the metric $d$ on $X$, we define a metric $d_{1}$ on $X \times X$ as

$$
d_{1}((x, y),(u, v))=d(x, u)+d(y, v) \quad \text { for }(x, y),(u, v) \in X \times X .
$$

Now, we denote $A^{*}=A \times A, B^{*}=B \times B, A_{0}^{*}=A_{0} \times A_{0}$, and $B_{0}^{*}=B_{0} \times B_{0}$. From the definition of the metric $d_{1}$, we have the following results. 
- $d_{1}\left(A^{*}, B^{*}\right)=d_{1}(A \times A, B \times B)=d(A, B)+d(A, B)$.

- Let $x=\left(x_{1}, y_{1}\right) \in A^{*}, y=\left(x_{2}, y_{2}\right) \in B^{*}$ such that $d_{1}(x, y)=d_{1}\left(A^{*}, B^{*}\right)$. Then $d\left(x_{1}, x_{2}\right)=d\left(y_{1}, y_{2}\right)=d(A, B)$.

Proof $d_{1}(x, y)=d_{1}\left(A^{*}, B^{*}\right)$ implies $d\left(x_{1}, x_{2}\right)+d\left(y_{1}, y_{2}\right)=d(A, B)+d(A, B)$. Since $d\left(x_{1}, x_{2}\right) \geq$ $d(A, B)$ and $d\left(y_{1}, y_{2}\right) \geq d(A, B)$, it follows $d\left(x_{1}, x_{2}\right)=d\left(y_{1}, y_{2}\right)=d(A, B)$.

$$
A_{0}^{*}=\left\{x=\left(x_{1}, y_{1}\right) \in A^{*}: d_{1}(x, y)=d_{1}\left(A^{*}, B^{*}\right) \text { for some } y=\left(x_{2}, y_{2}\right) \in B^{*}\right\}
$$

and

$$
B_{0}^{*}=\left\{y=\left(x_{2}, y_{2}\right) \in B^{*}: d_{1}(x, y)=d_{1}\left(A^{*}, B^{*}\right) \text { for some } x=\left(x_{1}, y_{1}\right) \in A^{*}\right\}
$$

It is to be noted that for every $x \in A_{0}^{*}$ there exists $y \in B_{0}^{*}$ such that $d_{1}(x, y)=d_{1}\left(A^{*}, B^{*}\right)$ and, conversely, for every $y \in B_{0}^{*}$ there exists $x \in A_{0}^{*}$ such that $d_{1}(x, y)=d_{1}\left(A^{*}, B^{*}\right)$.

We define a function $T: A^{*} \rightarrow B^{*}$ with the help of the function $F: A \times A \rightarrow B$ as follows:

$$
T x=T\left(x_{1}, y_{1}\right)=\left(F\left(x_{1}, y_{1}\right), F\left(y_{1}, x_{1}\right)\right) \quad \text { for } x=\left(x_{1}, y_{1}\right) \in A^{*} .
$$

Lemma 3.1 If the pair $(A, B)$ has P-property, then the pair $\left(A^{*}, B^{*}\right)$ has also the P-property.

Proof Suppose that for any $x_{1}=\left(u_{1}, v_{1}\right), x_{2}=\left(u_{2}, v_{2}\right) \in A_{0}^{*}=A_{0} \times A_{0}$, and $y_{1}=\left(r_{1}, s_{1}\right), y_{2}=$ $\left(r_{2}, s_{2}\right) \in B_{0}^{*}=B_{0} \times B_{0}$,

$$
\left.\begin{array}{l}
d_{1}\left(x_{1}, y_{1}\right)=d_{1}\left(A^{*}, B^{*}\right), \\
d_{1}\left(x_{2}, y_{2}\right)=d_{1}\left(A^{*}, B^{*}\right) .
\end{array}\right\}
$$

So

$$
\left.\begin{array}{l}
d_{1}\left(\left(u_{1}, v_{1}\right),\left(r_{1}, s_{1}\right)\right)=d_{1}(A \times A, B \times B), \\
d_{1}\left(\left(u_{2}, v_{2}\right),\left(r_{2}, s_{2}\right)\right)=d_{1}(A \times A, B \times B) ;
\end{array}\right\}
$$

that is,

$$
\left.\begin{array}{l}
d\left(u_{1}, r_{1}\right)+d\left(v_{1}, s_{1}\right)=d(A, B)+d(A, B), \\
d\left(u_{2}, r_{2}\right)+d\left(v_{2}, s_{2}\right)=d(A, B)+d(A, B),
\end{array}\right\}
$$

which implies that

$$
\left.\begin{array}{l}
d\left(u_{1}, r_{1}\right)=d\left(v_{1}, s_{1}\right)=d(A, B), \\
d\left(u_{2}, r_{2}\right)=d\left(v_{2}, s_{2}\right)=d(A, B) .
\end{array}\right\}
$$

Since the pair $(A, B)$ has the $P$-property, and $u_{1}, v_{1}, u_{2}, v_{2} \in A_{0}$ and $r_{1}, s_{1}, r_{2}, s_{2} \in B_{0}$,

$$
\left.\begin{array}{l}
d\left(u_{1}, r_{1}\right)=d(A, B), \\
d\left(u_{2}, r_{2}\right)=d(A, B)
\end{array}\right\} \quad \Rightarrow \quad d\left(u_{1}, u_{2}\right)=d\left(r_{1}, r_{2}\right)
$$


and

$$
\left.\begin{array}{l}
d\left(v_{1}, s_{1}\right)=d(A, B), \\
d\left(v_{2}, s_{2}\right)=d(A, B)
\end{array}\right\} \Rightarrow d\left(v_{1}, v_{2}\right)=d\left(s_{1}, s_{2}\right) .
$$

Therefore, $d\left(u_{1}, u_{2}\right)+d\left(v_{1}, v_{2}\right)=d\left(r_{1}, r_{2}\right)+d\left(s_{1}, s_{2}\right)$; that is, $d_{1}\left(\left(u_{1}, v_{1}\right),\left(u_{2}, v_{2}\right)\right)=d_{1}\left(\left(r_{1}, s_{1}\right)\right.$, $\left.\left(r_{2}, s_{2}\right)\right)$; that is, $d_{1}\left(x_{1}, x_{2}\right)=d_{1}\left(y_{1}, y_{2}\right)$.

Hence for any $x_{1}=\left(u_{1}, v_{1}\right), x_{2}=\left(u_{2}, v_{2}\right) \in A_{0}^{*}$ and $y_{1}=\left(r_{1}, s_{1}\right), y_{2}=\left(r_{2}, s_{2}\right) \in B_{0}^{*}$,

$$
\left.\begin{array}{l}
d_{1}\left(x_{1}, y_{1}\right)=d_{1}\left(A^{*}, B^{*}\right), \\
d_{1}\left(x_{2}, y_{2}\right)=d_{1}\left(A^{*}, B^{*}\right)
\end{array}\right\} \quad \Rightarrow \quad d_{1}\left(x_{1}, x_{2}\right)=d_{1}\left(y_{1}, y_{2}\right) .
$$

Therefore, the pair $\left(A^{*}, B^{*}\right)$ has the $P$-property.

Lemma 3.2 Let $F: A \times A \rightarrow B$ be a mapping with $F\left(A_{0} \times A_{0}\right) \subseteq B_{0}$. If $F$ has the proximal mixed monotone property on $A_{0} \times A_{0}$, then the mapping $T: A^{*} \rightarrow B^{*}$ is proximally increasing on $A_{0}^{*}$.

Proof Suppose that there exist $\left(x_{0}, y_{0}\right),\left(x_{1}, y_{1}\right),\left(u_{1}, v_{1}\right),\left(u_{2}, v_{2}\right) \in A_{0}^{*}=A_{0} \times A_{0}$ for which

$$
\left.\begin{array}{l}
\left(x_{0}, y_{0}\right) \preceq\left(x_{1}, y_{1}\right), \\
d_{1}\left(\left(u_{1}, v_{1}\right), T\left(x_{0}, y_{0}\right)\right)=d_{1}\left(A^{*}, B^{*}\right), \\
d_{1}\left(\left(u_{2}, v_{2}\right), T\left(x_{1}, y_{1}\right)\right)=d_{1}\left(A^{*}, B^{*}\right) .
\end{array}\right\}
$$

It follows that

$$
\left.\begin{array}{l}
x_{0} \preceq x_{1} \text { and } y_{0} \succeq y_{1}, \\
d\left(u_{1}, F\left(x_{0}, y_{0}\right)\right)+d\left(v_{1}, F\left(y_{0}, x_{0}\right)\right)=d(A, B)+d(A, B), \\
d\left(u_{2}, F\left(x_{1}, y_{1}\right)\right)+d\left(v_{2}, F\left(y_{1}, x_{1}\right)\right)=d(A, B)+d(A, B),
\end{array}\right\}
$$

which implies that

$$
\begin{aligned}
& x_{0} \preceq x_{1} \text { and } y_{0} \succeq y_{1}, \\
& d\left(u_{1}, F\left(x_{0}, y_{0}\right)\right)=d(A, B), \\
& d\left(u_{2}, F\left(x_{1}, y_{1}\right)\right)=d(A, B)
\end{aligned}
$$

and

$$
\left.\begin{array}{l}
x_{0} \preceq x_{1} \text { and } y_{0} \succeq y_{1}, \\
d\left(v_{1}, F\left(y_{0}, x_{0}\right)\right)=d(A, B), \\
d\left(v_{2}, F\left(y_{1}, x_{1}\right)\right)=d(A, B) .
\end{array}\right\}
$$

By hypothesis $F\left(A_{0} \times A_{0}\right) \subseteq B_{0}$, therefore $F\left(x_{1}, y_{0}\right) \in B_{0}$. Hence there exists $x_{1}^{*} \in A_{0}$ such that

$$
d\left(x_{1}^{*}, F\left(x_{1}, y_{0}\right)\right)=d(A, B) .
$$

Now we have

$$
\left.\begin{array}{l}
x_{0} \preceq x_{1}, \\
d\left(u_{1}, F\left(x_{0}, y_{0}\right)\right)=d(A, B), \\
d\left(x_{1}^{*}, F\left(x_{1}, y_{0}\right)\right)=d(A, B)
\end{array}\right\}
$$


and

$$
\left.\begin{array}{l}
y_{1} \preceq y_{0}, \\
d\left(u_{2}, F\left(x_{1}, y_{1}\right)\right)=d(A, B), \\
d\left(x_{1}^{*}, F\left(x_{1}, y_{0}\right)\right)=d(A, B) .
\end{array}\right\}
$$

Using the proximal mixed monotone property of $F$, we have

$$
u_{1} \preceq x_{1}^{*} \quad \text { and } \quad x_{1}^{*} \preceq u_{2} \quad \text { which implies that } \quad u_{1} \preceq u_{2} \text {. }
$$

Again, by hypothesis $F\left(A_{0} \times A_{0}\right) \subseteq B_{0}$, therefore $F\left(y_{0}, x_{1}\right) \in B_{0}$. Hence there exists $y^{*}{ }_{1} \in A_{0}$ such that

$$
d\left(y_{1}^{*}, F\left(y_{0}, x_{1}\right)\right)=d(A, B) .
$$

Now we have

$$
\left.\begin{array}{l}
x_{0} \preceq x_{1}, \\
d\left(v_{1}, F\left(y_{0}, x_{0}\right)\right)=d(A, B), \\
d\left(y_{1}^{*}, F\left(y_{0}, x_{1}\right)\right)=d(A, B)
\end{array}\right\}
$$

and

$$
\left.\begin{array}{l}
y_{1} \preceq y_{0}, \\
d\left(v_{2}, F\left(y_{1}, x_{1}\right)\right)=d(A, B), \\
d\left(y_{1}^{*}, F\left(y_{0}, x_{1}\right)\right)=d(A, B) .
\end{array}\right\}
$$

Using the proximal mixed monotone property of $F$, we have

$v_{1} \succeq y_{1}^{*} \quad$ and $\quad y_{1}^{*} \succeq v_{2} \quad$ which implies that $\quad v_{1} \succeq v_{2}$.

Therefore,

$$
\left.\begin{array}{l}
\left(x_{0}, y_{0}\right) \preceq\left(x_{1}, y_{1}\right), \\
d_{1}\left(\left(u_{1}, v_{1}\right), T\left(x_{0}, y_{0}\right)\right)=d_{1}\left(A^{*}, B^{*}\right), \\
d_{1}\left(\left(u_{2}, v_{2}\right), T\left(x_{1}, y_{1}\right)\right)=d_{1}\left(A^{*}, B^{*}\right)
\end{array}\right\} \Rightarrow \quad\left(u_{1}, v_{1}\right) \preceq\left(u_{2}, v_{2}\right) .
$$

Hence $T: A^{*} \rightarrow B^{*}$ is proximally increasing on $A_{0}^{*}$.

Theorem 3.1 Let $(X, \preceq)$ be a partially ordered set and suppose that there is a metric $d$ on $X$ such that $(X, d)$ is a complete metric space. Let $(A, B)$ be a pair of non-empty closed subsets of $X$ such that $A_{0}$ is non-empty closed and $(A, B)$ satisfies the P-property. Let $F: A \times A \rightarrow B$ be a mapping such that $F\left(A_{0} \times A_{0}\right) \subseteq B_{0}, F$ has proximal mixed monotone property on $A_{0} \times A_{0}$. Suppose that there exist $\psi \in \Psi$ and $\varphi, \theta \in \Theta$ such that (2.1) and (2.2) are satisfied and for all $(x, y),(u, v) \in A_{0} \times A_{0}$ with $(x, y) \succeq(u, v)$,

$$
\begin{aligned}
& \psi(d(F(x, y), F(u, v))+d(F(y, x), F(v, u))) \\
& \quad \leq \varphi(d(x, u)+d(y, v))-\theta(d(x, u)+d(y, v)) .
\end{aligned}
$$




\section{Suppose either}

(a) $F$ is continuous or

(b) $X$ has the following properties:

(i) if a nondecreasing sequence $\left\{x_{n}\right\} \rightarrow x$, then $x_{n} \preceq x$, for all $n \geq 0$;

(ii) if a nonincreasing sequence $\left\{y_{n}\right\} \rightarrow y$, then $y \preceq y_{n}$, for all $n \geq 0$.

Also, suppose that there exist $\left(x_{0}, y_{0}\right),\left(x_{1}, y_{1}\right) \in A_{0} \times A_{0}$ such that $d\left(x_{1}, F\left(x_{0}, y_{0}\right)\right)=d(A, B)$ and $d\left(y_{1}, F\left(y_{0}, x_{0}\right)\right)=d(A, B)$ with $\left(x_{0}, y_{0}\right) \preceq\left(x_{1}, y_{1}\right)$. Then $F$ has a coupled best proximity point in $A_{0} \times A_{0}$; that is, there exists an element $\left(x^{*}, y^{*}\right) \in A_{0} \times A_{0}$ such that $d\left(x^{*}, F\left(x^{*}, y^{*}\right)\right)=d(A, B)$ and $d\left(y^{*}, F\left(y^{*}, x^{*}\right)\right)=d(A, B)$.

Proof We consider the product space $(X \times X, \preceq)$, the metric $d_{1}$ on $X \times X$, and the function $T: A^{*} \rightarrow B^{*}$ as mentioned above. Denote $Y=X \times X$. By the definition of the metric $d_{1}$ and the function $T$, we have:

- $\left(Y, d_{1}\right)$ is a complete metric space,

- $\left(A^{*}, B^{*}\right)$ is a pair of non-empty closed subsets of $Y$ such that $A_{0}^{*}$ is non-empty closed and $\left(A^{*}, B^{*}\right)$ satisfies the $P$-property,

- $T\left(A_{0}^{*}\right) \subseteq B_{0}^{*}$

- $T$ is proximally increasing on $A_{0}^{*}$,

- $T$ is continuous,

- the condition (b) implies that if $\left\{x_{n}\right\}$ is a nondecreasing sequence in $Y$ such that $x_{n} \rightarrow x$, then $x_{n} \preceq x$ for all $n \geq 0$,

- let $p=(x, y), q=(u, v) \in A_{0} \times A_{0}$ such that $p \succeq q$; then (3.1) reduces to

$$
\psi\left(d_{1}(T p, T q)\right) \leq \varphi\left(d_{1}(p, q)\right)-\theta\left(d_{1}(p, q)\right)
$$

- now, the existence of $\left(x_{0}, y_{0}\right),\left(x_{1}, y_{1}\right) \in A_{0} \times A_{0}$ such that $d\left(x_{1}, F\left(x_{0}, y_{0}\right)\right)=d(A, B)$ and $d\left(y_{1}, F\left(y_{0}, x_{0}\right)\right)=d(A, B)$ with $\left(x_{0}, y_{0}\right) \preceq\left(x_{1}, y_{1}\right)$ implies the existence of points $p_{0}=\left(x_{0}, y_{0}\right), p_{1}=\left(x_{1}, y_{1}\right) \in A_{0}^{*}$ such that $d_{1}\left(p_{1}, T p_{0}\right)=d_{1}\left(A^{*}, B^{*}\right)$ with $p_{0} \preceq p_{1}$.

Therefore, the theorem reduces to Theorem 2.1 and hence $T$ has a best proximity point in $A_{0}^{*}$; that is, there exists an element $w^{*}=\left(x^{*}, y^{*}\right) \in A_{0}^{*}$ such that $d_{1}\left(w^{*}, T w^{*}\right)=d_{1}\left(A^{*}, B^{*}\right)$; that is, $d_{1}\left(\left(x^{*}, y^{*}\right), T\left(x^{*}, y^{*}\right)\right)=d_{1}(A \times A, B \times B)$; that is, $d\left(x^{*}, F\left(x^{*}, y^{*}\right)\right)+d\left(y^{*}, F\left(y^{*}, x^{*}\right)\right)=$ $d(A, B)+d(A, B)$, which implies that $d\left(x^{*}, F\left(x^{*}, y^{*}\right)\right)=d(A, B)$ and $d\left(y^{*}, F\left(y^{*}, x^{*}\right)\right)=d(A, B)$; that is, $\left(x^{*}, y^{*}\right) \in A_{0} \times A_{0}$ is coupled best proximity point of $F$.

The following theorem gives the uniqueness of the result in Theorem 3.1 under certain conditions.

Theorem 3.2 In addition to the hypotheses of Theorem 3.1, suppose that for every $(x, y),\left(x^{*}, y^{*}\right) \in A_{0} \times A_{0}$ there exists a $(u, v) \in A_{0} \times A_{0}$ such that $(u, v)$ is comparable to $(x, y)$ and $\left(x^{*}, y^{*}\right)$. Then $F$ has a unique coupled best proximity point.

Note that several coupled proximity point results can be obtained corresponding to Corollaries 2.1-2.3 if we assume the particular forms of the control functions used therein. 
Authors' contributions

The authors contributed equally to this work and read and approved the final manuscript.

\section{Author details}

'Department of Mathematics, Indian Institute of Engineering Science and Technology, Shibpur, Howrah, West Bengal 711103, India. ${ }^{2}$ Department of Mathematics, Sovarani Memorial College, Jagatballavpur, Howrah, West Bengal 711408, India. ${ }^{3}$ Department of Mathematics and Informatics, University Politehnica of Bucharest, Bucharest, 060042, Romania. ${ }^{4}$ Department of Mathematics, NITMAS, South 24 Pargana, Kolkata, West Bengal 743368, India.

Received: 4 June 2015 Accepted: 8 September 2015 Published online: 18 September 2015

\section{References}

1. Eldred, AA, Veeramani, P: Existence and convergence of best proximity points. J. Math. Anal. Appl. 323, 1001-1006 (2006)

2. Miandaragh, MA, Postolache, M, Rezapour, S: Approximate fixed points of generalized convex contractions. Fixed Point Theory Appl. 2013, Article ID 255 (2013)

3. Fan, K: Extensions of two fixed point theorems of F.E. Browder. Math. Z. 122, 234-240 (1969)

4. Abkar, A, Gabeleh, M: Global optimal solutions of noncyclic mappings in metric spaces. J. Optim. Theory Appl. 153, 298-305 (2012)

5. Abkar, A, Gabeleh, M: Best proximity points of non-self mappings. Top 21, 287-295 (2013)

6. Basha, SS: Best proximity points: optimal solutions. J. Optim. Theory Appl. 151, 210-216 (2011)

7. Basha, SS: Discrete optimization in partially ordered sets. J. Glob. Optim. 54, 511-517 (2012)

8. Caballero, J, Harjani, J, Sadarangani, K: A best proximity point theorem for Geraghty-contractions. Fixed Point Theory Appl. 2012, Article ID 231 (2012)

9. Choudhury, BS, Maity, P, Konar, P: A global optimality result using nonself mappings. Opsearch 51, $312-320$ (2014)

10. Choudhury, BS, Maity, P, Konar, P: A global optimality result using Geraghty type contraction. Int. J. Optim. Control, Theor. Appl. 4, 99-104 (2014)

11. Choudhury, BS, Maity, P, Metiya, N: Best proximity point theorems with cyclic mappings in set valued analysis. Indian J. Math. 57, 79-102 (2015)

12. Karapinar, E: On best proximity point of $\psi$-Geraghty contractions. Fixed Point Theory Appl. 2013, Article ID 200 (2013)

13. Karpagam, S, Agrawal, S: Best proximity points for cyclic Meir-Keeler contraction maps. Nonlinear Anal. 74, 1040-1046 (2011)

14. Kutbi, MA, Chandok, S, Sintunavarat, W: Optimal solutions for nonlinear proximal $C_{N}$-contraction mapping in metric space. J. Inequal. Appl. 2014, Article ID 193 (2014)

15. Mongkolkeha, C, Sintunavarat, W: Best proximity points for multiplicative proximal contraction mapping on multiplicative metric spaces. J. Nonlinear Sci. Appl. 8(6), 1134-1140 (2015)

16. Sankar Raj, V: A best proximity point theorem for weakly contractive non-self-mappings. Nonlinear Anal. 74 4804-4808 (2011)

17. Banach, S: Sur les oprations dans les ensembles abstraits et leurs applications aux equations intgrales. Fundam. Math. 3, 133-181 (1922)

18. Kirk, WA, Sims, B: Handbook of Metric Fixed Point Theory. Kluwer Academic, Dordrecht (2001)

19. Alber, YI, Guerre-Delabriere, S: Principles of weakly contractive maps in Hilbert spaces. In: Goldberg, I, Lyubich, Y (eds.) New Results in Operator Theory and Its Applications. Operator Theory: Advances and Applications, vol. 98, pp. 7-22. Birkhäuser, Basel (1997)

20. Rhoades, BE: Some theorems on weakly contractive maps. Nonlinear Anal. 47(4), 2683-2693 (2001)

21. Chandok, S, Choudhury, BS, Metiya, N: Fixed point results in ordered metric spaces for rational type expressions with auxiliary functions. J. Egypt. Math. Soc. 23, 95-101 (2015)

22. Chidume, CE, Zegeye, H, Aneke, SJ: Approximation of fixed points of weakly contractive nonself maps in Banach spaces. J. Math. Anal. Appl. 270(1), 189-199 (2002)

23. Choudhury, BS, Konar, P, Rhoades, BE, Metiya, N: Fixed point theorems for generalized weakly contractive mappings. Nonlinear Anal. 74, 2116-2126 (2011)

24. Choudhury, BS, Metiya, N, Postolache, M: A generalized weak contraction principle with applications to coupled coincidence point problems. Fixed Point Theory Appl. 2013, Article ID 152 (2013)

25. Dorić, D: Common fixed point for generalized $(\psi, \varphi)$-weak contractions. Appl. Math. Lett. 22, 1896-1900 (2009)

26. Dutta, PN, Choudhury, BS: A generalisation of contraction principle in metric spaces. Fixed Point Theory Appl. 2008 Article ID 406368 (2008)

27. Harjani, J, Sadarangani, K: Fixed point theorems for weakly contractive mappings in partially ordered sets. Nonlinear Anal. 71, 3403-3410 (2009)

28. Kamran, T, Ali, MU: Fixed point theorems for mappings satisfying a new contractive type condition. J. Adv. Math. Stud. 6(2), 115-122 (2013)

29. Nashine, HK, Samet, B: Fixed point results for mappings satisfying $(\psi, \phi)$-weakly contractive condition in partially ordered metric spaces. Nonlinear Anal. 74, 2201-2209 (2011)

30. Zhang, Q, Song, Y: Fixed point theory for generalized $\phi$-weak contractions. Appl. Math. Lett. 22, 75-78 (2009)

31. Gnana Bhaskar, T, Lakshmikantham, V: Fixed point theorems in partially ordered metric spaces and applications. Nonlinear Anal. 65, 1379-1393 (2006)

32. Guo, D, Lakshmikantham, V: Coupled fixed points of nonlinear operators with applications. Nonlinear Anal. 11, 623-632 (1987)

33. Choudhury, BS, Kundu, A: Two coupled weak contraction theorems in partially ordered metric spaces. Rev. R. Acad. Cienc. Exactas Fís. Nat., Ser. A Mat. 108, 335-351 (2014)

34. Abkar, A, Ghods, S, Azizi, A: Coupled best proximity point theorems for proximally g-Meir-Keeler type mappings in partially ordered metric spaces. Fixed Point Theory Appl. 2015, Article ID 107 (2015) 
35. Kumam, P, Pragadeeswarar, V, Marudai, M, Sitthithakerngkiet, K: Coupled best proximity points in ordered metric spaces. Fixed Point Theory Appl. 2014, Article ID 107 (2014)

36. Sintunavarat, W, Kumam, P: Coupled best proximity point theorem in metric spaces. Fixed Point Theory Appl. 2012 Article ID 93 (2012)

37. Shatanawi, W, Pitea, A: Best proximity point and best proximity coupled point in a complete metric space with (P)-property. Filomat 29(1), 63-74 (2015)

Submit your manuscript to a SpringerOpen ${ }^{\circ}$ journal and benefit from:

- Convenient online submission

- Rigorous peer review

- Immediate publication on acceptance

- Open access: articles freely available online

- High visibility within the field

- Retaining the copyright to your article

Submit your next manuscript at $\boldsymbol{s p r i n g e r o p e n . c o m ~}$ 